\title{
Controle biológico de simulídeos (Diptera: Simuliidae): panorama e perspectivas
}

Biological control of black flies (Diptera: Simuliidae): overview and perspectives

\author{
${ }^{1}$ Amanda Maia \\ ${ }^{1}$ Ida Carolina Neves Direito \\ ${ }^{2}$ Ronaldo Figueiró
}

1 Laboratório de Biotecnologia Ambiental, Centro Universitário Estadual da Zona Oeste (UEZO), Rio de Janeiro - RJ, Brasil;

2 Laboratório de Simulídeos e Oncocercose, Fundação Oswaldo Cruz, Rio de Janeiro - RJ; * Professor dos cursos de Ciências Biológicas, Engenharia Ambiental e Mestrado Profissional em Ensino de Ciências da Saúde e do Meio Ambiente. Centro Universitário de Volta Redonda - UniFOA, Volta Redonda - RJ, Brasil.

\section{RESUMO}

Os simulídeos (Diptera: Simuliidae) compreendem uma família de insetos holometábolos que possuem espécies vetoras da Oncocercose e da Mansonelose. Neste artigo é estabelecido um panorama sobre o controle biológico desses organismos, apresentando e discutindo as vantagens e desvantagens desse método sobre o controle químico.

\section{PALAVRAS-CHAVE:}

Simuliidae; bacillus thuringiensis; controle biológico.

\section{ABSTRACT}

Black flies (Diptera: Simuliidae) are an insect family that comprises Onchocerciasis and Mansonelosis vectors. In this article we draw an overview of the state of the art of biological control of these organisms, presenting and discussing the advantages and disadvantages of this form of control over chemical control.

\section{KEYWORDS:}

Simuliidae; bacillus thuringiensis; biological control.

\section{Como você deve citar?}

MAIA, A.; DIREITO, I. C. N., FIGUEIRÓ, R. Controle biológico de simulídeos (Diptera: Simuliidae): panorama e perspectivas. Cadernos UniFOA, Volta Redonda, n² 25, quadrimestral, p. 89-104, ago. 2014. 


\section{INTRODUÇÃO}

Simulídeos são dípteros nematóceros da família Simuliidae, conhecidos como piuns ou borrachudos. São insetos holometábolos (apresentam os estágios de ovo, larva, pupa e adulto), completam seu ciclo biológico em meio terrestre e aquático e suas larvas estão entre os componentes mais numerosos dos ecossistemas lóticos, pois têm grande potencial colonizador, com espécies capazes de colonizar diversos substratos novos em poucas horas (KIEL et al., 1998).

Seus imaturos são encontrados em água corrente de diferentes volumes, velocidades, temperatura, $\mathrm{pH}$ e altitude, a partir do nível do mar (CROSSKEY, 1990; COSCARÓN, 1991), com aproximadamente 2132 espécies válidas (ADLER \& CROSSKEY, 2012). No Brasil, 90 espécies já se encontram identificadas (PEPINELLI et al., 2003) sendo 86 pertencentes ao gênero Simulium e quatro ao gênero Lutzsimulium (CROSSKEY \& HOWARD, 2004). Grande parte dessas espécies são antropofílicas, podendo causar alergias e transmitir doenças durante o repasto sanguíneo (STRIEDER \& CORSEUIL, 1992).

Embora esses organismos sejam considerados cosmopolitas, sua distribuição pode ser restrita localmente pela existência de criadouros com as condições apropriadas, uma vez que estes fazem uso de ecossistemas lóticos de águas claras e com baixo grau de contaminação para a criação dos seus imaturos (COSCARÓN, 1981). Como suas larvas se criam em ambientes lóticos em áreas de correnteza, esses insetos não se fazem presentes em algumas ilhas e desertos pela inexistência de água corrente (CROSSKEY, 1990).

As fêmeas de Simulídeos ovipositam, em média, massas de 200 a 300 ovos (ARAÚJO-COUTINHO \& LACEY, 1990) por postura, em substratos específicos, como galhos, folhas e pedras localizados próximos à superfície da água de cachoeiras, rios ou córregos (BABA \& TAKAOKA, 1991). A eclosão das larvas dá-se, normalmente, após 5 a 6 dias da postura, dependendo da temperatura da água e da espécie (ARAÚJO-COUTINHO \& LACEY, 1990). As larvas têm de 3 a $12 \mathrm{~mm}$ de comprimento, corpo alongado e alargado no abdome, uma cápsula cefálica bem desenvolvida, pentes cefálicos, antenas finas, papilas anais e um disco de ganchos com o qual se prende substrato (CUMMINS, 1973). Podem ter comportamento raspador, mas geralmente apresentam comportamento filtrador não seletivo (CUMMINS, 1973), sendo sua alimentação constituída basicamente de partículas sestônicas (CHANCE,1970). Fixam-se e locomovem-se aderidos aos substratos através de uma teia, produzida por substância salivar (COSCARÓN,1981), sempre em locais com grande fluxo de água, que favorecem a proliferação de microorganismos, que servindo como alimento desses insetos (WALLACE \& MERRITTI, 1980). As larvas realizam várias mudas de pele (ecdise) para crescer, passando por 6 a 9 estádios, dependendo da espécie. Segundo Adler \& McCreadie (1997) essas larvas são um dos principais habitantes da fauna de macroinvertebrados em ambientes lóticos.

Os adultos machos se alimentam de sulco vegetal, enquanto que os adultos fêmeas apresentam hábitos antropofílicos ou zoofílicos, principalmente, nos períodos da manhã e tarde (CROSSKEY, 1955). Estas se fixam à pele do hospedeiro com sua boca e a perfura com suas mandíbulas, procedendo, em seguida, com a liberação de saliva sobre a ferida para evitar a coagulação do sangue (CROSSKEY, 1955). 0 repasto sanguíneo das fêmeas está também associado à maturação dos oócitos, complementando o de ciclo gonotrófico (CROSSKEY, 1955).

Fêmeas de simulídeos estão entre os hematófagos mais incômodos ao ser humano e outros animais, pois, além dessa sensação, causam lesões ao picarem partes do corpo, podendo também ser vetores de doenças transmitidas por diversos agentes etiológicos como bactérias, helmintos, protozoários, nematóides e vírus (PINTO, 1931; LANE, 1949; DALMAT, 1955; ANDERSON, 1961; CERQUEIRA, 1967; 
CROSSKEY, 1990; HAMADA, 1993). Dentre as doenças vetoradas por Simulídeos, destacam-se oncocercose, mansonelose e penfigo-foliáceo.

Segundo Neves (1991), as espécies Simulium guianense, Simulium oyapockense, e Simulium roraimense são apontadas como vetoras da oncocercose, doença causada pela microfilaria Onchocerca volvulus Leuckart, 1893, que se desenvolve no interior do inseto, após a ingestão de sangue contaminado e é transmitida ao homem através da picada. Essas microfilárias podem permanecer na derme provocando oncocercomas (nódulos subcutâneos), coceira, despigmentação e perda da elasticidade, ou migrar para o tecido conjuntivo, como o ocular, formando aglomerados de adultos e podendo causar perda de visão decorrente de reações inflamatórias (REY, 2008).

Outra microfilária transmitida pelos simulídeos ao homem é a Mansonela ozzardi Manson, 1897, causadora da Mansonelose. Essa doença ocorre quando as microfilárias vão para o sistema linfático e cavidade abdominal, instalando-se em membranas pericárdicas e no sistema nervoso central, provocando febre, dores de cabeça e nas articulações, além de coceiras (MEDEIROS et al., 2009).

Aos simulídeos, em especial ao Simulium nigrimanum Macquart, 1838, também está associada a doença de caráter autoimune, crônica e endêmica em algumas regiões do mundo, chamada PenfigoFoliáceo, também conhecida como fogo selvagem (SAMPAIO et al., 1994; DELMONTES et al., 2001). Essa doença é caracterizada pelo aparecimento de bolhas superficiais ou profundas pelo corpo, que depois de um tempo se rompem levando a perda de pele, o que deixa as feridas comumente em "carne viva" (EATON et al., 1998).

A capacidade vetorial ou a acentuada zoofilia e antropofilia que algumas espécies apresentam as colocam na categoria de insetos daninhos em várias regiões do planeta, inclusive no Brasil (CROSSKEY, 1990). Os simulídeos afetam atividades turísticas e agropecuárias em regiões que apresentam alta incidência do inseto pelo incômodo causado por sua picada (AMARAL-CALVÃO \& MAIAHERZOG, 2003; GIL-AZEVEDO et al., 2004; FIGUEIRÓ et al., 2006a).

Devido a sua grande importância no âmbito médico-sanitário e socioeconômico, o controle de Simulídeos faz-se necessário e é realizado desde a década de 70 (ARAÚJO-COUTINHO et al., 1999). 0 controle é realizado sobre as formas imaturas do inseto, a fim de interromper o ciclo biológico dos simulídeos, podendo ser empregados diferentes métodos de controle.

\section{MÉTODOS DE CONTROLE APLICADOS A DÍPTEROS SIMULIIDAE}

A grande maioria dos métodos utilizados para controlar as populações de simulídeos visa ao ataque às fases imaturas por estas estarem fixas em substratos de ambientes lóticos. Ainda assim, existe a dificuldade de controle desses insetos por falta de conhecimentos bioecológicos das espécies alvo, da eficiência dos agentes de controle (ANDRADE, 1988) e de serem pouco conhecidos os padrões de preferência de mesohabitat e microhabitat de larvas de simulídeos na maioria dos biomas (SANTOS-JR et al., 2007; FIGUEIRÓ et al., 2008; BERTAZO \& FIGUEIRÓ, 2012; FIGUEIRÓ et al., 2012). Dentre as formas mais utilizadas como controle desdes insetos, destacam-se o controle químico, realizado através do emprego de inseticidas, e o controle biológico.

O controle químico é realizado através do uso de substâncias tóxicas (ingredientes ativos) na família Simuliidae presente nos pesticidas (agrotóxicos) sintéticos. Esses pesticidas podem ter ação inseticida, quando age sobre o inseto adulto, ou larvicida, quando age sobre a fase imatura do inseto. Os ingredientes ativos com ação larvicida das classes dos organoclorados, como o DDT (diclorodi- 
feniltricloretano) e o BHC (Hexaclorociclo-hexano), e dos organofosforados, como o temefós, foram comumente utilizados para controle de simulídeos no século passado. Entretanto, geraram resistência a esses ingredientes ativos que resultaram na gradativa redução de sua eficácia no controle (ARAÚJOCOUTINHO et al., 2004).

O desenvolvimento de resistência aos inseticidas nas populações associado a: i) diminuição na população de inimigos naturais, uma vez que os pesticidas não eram específicos para simulídeos; ii) riscos a saúde de homens e animais devido às frequentes aplicações desses produtos; iii) contaminação dos lençóis freáticos e, iv) diminuição da biodiversidade nos locais de aplicação (LACEY et al., 2001), tem levado à avaliação de métodos alternativos ao controle químico, entre eles o controle biológico (RUAS NETO, 1984a,b; RUAS NETO et al., 1985; ARAÚJO-COUTINHO et al., 2004).

Os processos de controle biológico atuam bioquímica/fisiologicamente, visando à redução da densidade populacional pela influência de outra população que possa agir nesse sentido, sendo dessa forma específico (FORATTINI, 2002). A avaliação do potencial predador de anelídeos, celenterados, crustáceos, insetos, ácaros, anfíbios, peixes, pássaros, fungos e bactérias sobre os simulídeos vêm sendo realizada (GINARTE et al., 2003; ARAÚJO-COUTINHO et al., 2004; NASCIMENTO et al., 2007), no entanto, apenas os estudos com bactérias do gênero Bacillus foi bem sucedido (CAMPOS \& ANDRADE, 2001). Para que outros organismos possam ser empregados como agentes de controle biológico, são necessários maiores investimentos em experimentações que permitam uma adequada avaliação do desempenho destes em condições de laboratório e de campo (CAMPOS \& ANDRADE, 2001).

Para a aplicação desses processos devem-se considerar fatores ecológicos e socioeconômicos, a eficácia do agente deve ser testada e a viabilidade de produção em grande escala do inimigo natural deve ser avaliada (FORATTINI, 2002). Em formas imaturas de simulídeos o controle biológico tem sido feito através do emprego de biolarvicidas, ou seja, produtos com substâncias de origem biológica e/ ou microrganismos com ação larvicida.

\section{CONTROLE BIOLÓGICO DE SIMULIÍDEOS COM BIOLARVICIDAS}

O controle biológico de simulídeos com biolarvicidas tem sido amplamente utilizado, sendo a espécie bacteriana Bacillus thuringiensis (Bt) usada como princípio ativo desses produtos (ARAÚJOCOUTINHO et al., 2005). Essa bactéria é encontrada no solo e pode ser adicionada a um ecossistema para realizar o controle populacional de insetos (ANDREWS et al.,1987; STAHLY et al., 1991; VILASBOAS et al., 2007). Produtos à base de Bt podem utilizar bactérias na forma como naturalmente são encontradas ou submetê-las à manipulação em laboratório, de forma a inativar características que não são de interesse (VILAS-BOAS et al., 2007).

Bacillus thuringiensis é uma bactéria gram positiva, aeróbica ou facultativamente anaeróbica, de forma cilíndrica, formadora de esporos e que apresenta alta toxicidade contra alguns tipos de insetos (VILAS-BOAS et al., 2007). Os sorotipos Bacillus thuringiensis aizawai, Bacillus thuringiensis israelensis, Bacillus thuringiensis kurstaki e Bacillus thuringiensis tenebrionis são utilizados como base para produtos recomendados para combater a população de diversos insetos das ordens Coleoptera, Diptera, Hemiptera e Lepidoptera (GLARE \& O' CALLAGHAN, 1998; JOUNG \& COTÉ, 2000).

Biolarvicidas com princípio ativo à base de bactérias do gênero Bacillus têm sido utilizados mundialmente em larga escala por sua patogenicidade e especificidade sobre larvas de simulídeos (LACEY \& LACEY, 1981; BECKER et al., 1992; BROWN et al., 1998a,b; BROWN et al., 1999; RODRIGUES et al., 1998; NAYAR et al.,1999; BROWN et al., 2000; CHUNG et al., 2001; FILLINGER et al., 2003; CAVADOS et al., 2005). 
Produtos à base de Bt são altamente seletivos, não fitotóxicos, não permanecem no ambiente por muito tempo após sua ação, suas formulações, geralmente, têm boa resistência às condições adversas e, segundo Glare \& O' Callaghan (1998), esse biolarvicida não causa danos às pessoas, animais, peixes ou quaisquer outros organismos não alvos.

Em paralelo aos estudos sobre o $\mathrm{Bt}$, outros agentes entomopatogênicos têm sido estudados, como microsporídeos (ARAÚJO-COUTINHO et al., 2004; NASCIMENTO et al., 2007) e nematódeos (GINARTE et al., 2003), com vistas ao chamado manejo integrado, ou seja, o conhecimento de padrões de epizootia e enzootia de agentes entomopatogênicos naturais pode ampliar a eficiência do controle por Bt, permitindo a identificação de momentos mais apropriados para sua aplicação.

Dentre as espécies de Bt, uma vem se destacando quanto aos resultados obtidos no controle de simulídeos e já é empregada comercialmente, a Bacillus thuringiens israelensis (VILAS-BOAS et al., 2007), isolada pela primeira vez a partir de uma amostra de solo em Israel, na década de 70 (BRAVO et al., 2007). Ela foi identificada e denominada Bacillus thuringiens israelensis (Bti), sorotipo H-14 (BARJAC, 1978), sendo considerada específica no combate a espécies de Culicidae e Simuliidae. No entanto, somente após registros de resistência de imaturos de simulídeos aos larvicidas organoclorados (DDT), na África, no final da década de 70, investiu-se mais arduamente no desenvolvimento de formulações de Bti para o controle de simulídeos (JAMNBACK, 1981).

No Brasil, desde a década de 1980, tem-se pesquisado novas metodologias de controle entomológico com biolarvicidas, sendo desenvolvidos programas internacionais para a utilização de Bacillus thuringiensis sorotipo israelensis (Bti) no controle de dípteros Simuliidae. A utilização se deu, inicialmente, no Rio Grande do Sul (RUAS NETO et al., 1984; RUAS NETO et al., 1985; SOUZA et al., 1994), no estado de São Paulo (ARAÚJO-COUTINHO \& LACEY, 1990; ANDRADE \& CASTELLO- BRANCO JR., 1991) e no Paraná (LOZOVEI et al.,1992; CUNHA \& BASSI,1997).

\section{MODO DE AÇÃO DO BACILLUS THURINGIENSIS ISRAELENSIS (BTI)}

A bactéria Bacillus thuringiensis sintetiza, durante a fase de esporulação, proteínas que se acumulam na periferia dos esporos na forma de cristais em um dos polos da célula (LERECLUS, 1988; HÖFTE \& WHITELEY, 1989; PEFERÖEN, 1997). Tais cristais são compostos por uma ou várias proteínas, chamadas delta-endotoxinas, Cry ou Insecticidal Crystal Proteins (ICPs), que são altamente tóxicas, específicas e, por isso, inócuas para a maioria dos outros organismos, incluindo insetos benéficos (HERRERO et al., 2001; SIEGEL, 2001). Os produtos à base de Bacillus thuringiensis israelensis (Bti) contêm esporos e cristais proteicos da bactéria, que devem ser solubilizados em meio alcalino entérico, pois tornam-se ativos contra as populações de insetos através da ingestão do produto pelas formas imaturas (VILARINHOS et al., 2003). Ao ingerir os cristais, estes são dissolvidos no trato intestinal da larva e as delta-endotoxinas constituintes destes são solubilizadas e proteoliticamente, convertidas em polipeptídeos menores (VILARINHOS et al., 2003). Os polipeptideos de delta-endotoxinas ligamse aos receptores de ligação presentes nas microvilosidades da parede intestinal da larva, formando poros na camada epitelial do intestino médio que perde sua integridade, rompendo-se (FIUZA et al.,1996; SCHNEPF et al., 1998). Isso faz com que as larvas parem de se alimentar, levando-as à morte por inanição ou septicemia.

Segundo Chilcott et al. (1990), as larvas deixam de se alimentar dentro de uma hora após a ingestão do biolarvicida à base de Bti, apresentando atividade reduzida após duas horas, lentidão extrema até quatro horas passadas da ingestão do produto e paralisia geral seis horas depois de ingerido o biolarvi- 
cida. Na maioria das vezes, a morte larval ocorre em menos de 24 horas (GLARE \& O' CALLAGHAN, 1998; JOUNG \& COTÉ, 2000; JEAN-FRANÇOIS \& NIELSEN-LEROUX, 2000).

Apesar da elevada eficiência e especificidade do produto, estudos apontam que a utilização de produtos à base de Bti no controle biológico tem limitações, que são decorrentes da suscetibilidade dos cristais formados durante a esporulação às condições climáticas e radiações ultravioletas que podem inativá-los e, consequentemente, a ação do produto (BRAVO et al., 2007). Além disso, os biolarvicidas à base de Bti, por não possuírem ação residual, uma vez que não são persistentes no ambiente, e apresentarem sua eficiência decorrente de todo um procedimento adequado de aplicação, em alguns casos, precisam ser substituídos por agentes de controle químico para que o controle possa ser realizado (BRAVO et al., 2007).

\section{APLICAÇÃO DO BIOLARVICIDA À BASE DE BACILLUS THURINGIENSIS ISRAELENSIS (BTI)}

Antes da aplicação de quaisquer pesticidas, é importante que haja avaliação do ambiente, da cobertura vegetal, tipo do solo, topografia e geologia, distribuição temporal e espacial das precipitações pluviométricas e de outras variáveis do clima, das populações de espécies presentes no local, do impacto ambiental e da ação do produto em organismos não alvo (ARAÚJO-COUTINHO et al., 1999). A eficiência na utilização de biolarvicidas no controle das larvas de simulídeos requer uma metodologia correta da medida de vazão dos cursos de água e da dosagem adequada do produto biológico a ser utilizado, pois cada ambiente possui características que influenciam diretamente nas oscilações da vazão de água (SILVEIRA et al., 1998). Em córregos de pequenas bacias hidrográficas, devido à pequena capacidade de armazenamento de água no interior da bacia e o menor efeito de regularização dos escoamentos, essas características influenciam com maior intensidade as oscilações na vazão da água (SILVEIRA et al., 1998). A estrutura física do ambiente desempenha um importante papel na determinação do número e tipos de organismos que podem sobreviver (SILVEIRA et al., 1998), influenciando também a população de simulídeos.

A estratégia de aplicação corresponde ao principal fator que garante o sucesso do Bti; logo, é de extrema importância que, na implantação de controle entomológico em água corrente, haja conhecimento das características dos cursos de água, possibilitando a determinação da dose ideal do biolarvicida à base de Bti. Por essa razão, como primeiro passo para aplicação desse método de controle, deve-se realizar o levantamento hidrológico e o estudo hidrográfico das localidades a serem tratadas, indicando o curso de água principal e seus afluentes (ANDRADE, 2008).

A velocidade da correnteza tem importância vital na medida em que muitos invertebrados aquáticos precisam dela para sua alimentação ou por exigências respiratórias (HYNES, 1974; KIKUCHI \& UIEDA, 1998). A vazão também influencia a morfologia e hidrografia do rio: havendo grande vazão, há pouca distinção entre áreas de remanso e de correnteza e também pouca retenção de água (KIKUCHI \& UIEDA, 1998), de forma que aliada à correnteza, a vazão elevada pode remover as pedras do fundo do ambiente lótico, resultando na remoção dos organismos e substratos (KIKUCHI \& UIEDA, 1998). Por outro lado, quando a vazão é pequena, a heterogeneidade das águas é maior, apresentando nítidas áreas de retenção e correnteza que exercem efeito direto sobre os organismos através da ação sobre a natureza do substrato e, desse modo, atuando indiretamente sobre a composição das comunidades de macroinvertebrados (KIKUCHI \& UIEDA, 1998).

Dessa forma, o cálculo da vazão se faz necessário, sendo o resultado obtido multiplicado pela concentração do produto a ser aplicada em cada curso da Bacia Hidrográfica para obter a quantidade 
ideal do biolarvicida. A fórmula utilizada para esse cálculo é $D=Q \times C$; em que: $D$, dose do larvicida Bti em $\mathrm{mL}$; $\mathrm{Q}$, vazão do curso de água em $\mathrm{m}^{3} \cdot \mathrm{min}^{-1} ; \mathrm{e}, \mathrm{C}$, concentração do larvicida Bti em ppm (ANDRADE \& CASTELLO-BRANCO JR., 1991).

A aplicação do biolarvicida é realizada com a utilização de um regador com água e o produto, na quantidade determinada pelas equações. Segundo Lacey \& Undeen (1984), o tempo ideal e mais eficiente para aplicação é de um minuto a um minuto e meio.

\section{BIOENSAIOS COM CRIADOUROS ARTIFICIAIS EM LABORATÓRIO}

Para desenvolvimento de formulações à base de Bt, bioensaios em laboratório foram e são fundamentais, pois possibilitam constantes avaliações e melhorias na eficácia, estabilidade, facilidade de aplicação e atividade residual do produto $(\mathrm{COUCH}, 2000)$. Para o sucesso dos resultados, os bioensaios necessitam de reproduções fiéis das condições de campo em laboratório, inclusive o controle do tempo de contato entre as larvas de simulídeos. 0 produto deve ser utilizado, levando-se em consideração que, em ambientes naturais, as larvas estão presentes em água corrente que carrega o produto durante seu fluxo.

Os bioensaios podem ser aplicados em sistema fechado ou aberto. Nos sistemas fechados, Pegoraro (1989) diz que é necessário haver circulação constante da água, o que pode ser feito através de um aumento da circulação de água pela produção de bolhas (LACEY \& MULLA, 1977), de bases magnéticas giratórias (COLBO \& THOMPSON, 1978) ou por meio de rotação de garrafas de plástico em copos de cera (HEMBREE et al., 1980). Ainda segundo Pegoraro (1989), a alimentação da larva deve ser com fitoplâncton e rações; enquanto outros autores relatam que a alimentação dos imaturos em sistemas fechados pode ser feita com utilização de ração de peixe como suplemento alimentar (ZHANG, 2006; VOJVODIC et al., 2006) ou mesmo levedura (HART et al.,1991; FREDEEN,1959). Nos sistemas abertos, as larvas são mantidas em um canal de água corrente com pouca profundidade (HARTLEY, 1955; MUIRHEAD-THOMSON, 1957; JAMNBACK \& FREMPONG-BOADU, 1966; GAUGLER et al.,1980).

Para eliminação da água contaminada com larvicida e substituição desta por água limpa, em ambos os tipos de sistemas, há certa complexidade. Para ambientes abertos foi desenvolvido um aparelho com um funil fundido a um recipiente de vidro, com um tubo de extravasamento e um orifício que permite a substituição gradual da água contaminada por água limpa enriquecida com alimento para as larvas (LACEY \& MULLA,1977). No entanto, isso possui um custo alto e é de difícil construção por requerer uma grande disponibilidade de espaço tal como o equipamento utilizado por Jamnback \& Frempong-Boadu (1966).

Estão descritas na literatura metodologias mais simples para a reprodução das condições de campo, como a utilização de aquários modificados (VIVIANI \& ARAUJO-COUTINHO, 1999; FIGUEIRÓ et al., 2006b), nos quais a água proveniente do criadouro é constantemente bombeada, ou ainda, o uso de copos plásticos de $300 \mathrm{ml}$.

O criadouro artificial descrito por Figueiró et al. (2006b) faz uso de um aquário modificado com um pequeno reservatório na parte superior, para o qual a água é bombeada constantemente a partir do fundo. Essa água bombeada então flui por três canais com diferentes inclinações e, assim, proporciona três diferentes condições de correnteza para cada velocidade da bomba. Esse criadouro, quando utilizado para bioensaios, pode ser temporariamente convertido para um sistema aberto, bastando abrir seu ralo para permitir que a água com o larvicida saia do sistema após a aplicação, como ocorreria em um rio, enquanto a nova água é inserida no sistema para substituí-la. 
Já o método de bioensaio com copos plásticos, descrito por Araújo-Coutinho et al. (2005), consiste da separação das larvas em grupos iguais por recipientes de $300 \mathrm{ml}$ acoplados a uma bomba que permita a circulação da água, cada qual contendo $200 \mathrm{ml}$ de água retirada do criadouro natural, para que não haja a necessidade de adição de alimentos artificiais e para que as condições estejam mais próximas da natureza. Enquanto o método proposto por Araújo-Coutinho et al. (2005) é relativamente mais simples, o mesmo não permite avaliar como diferentes condições hidrológicas podem afetar a ação dos larvicidas.

\section{PROGRAMAS PARA CONTROLE BIOLÓGICO DE SIMULÍDEOS}

O controle de simulídeos tem ocorrido com frequência no mundo todo, devido ao interesse médico e econômico. Em algumas localidades, os simulídeos se apresentam em grande densidade, atuando como vetores de organismos patogênicos e como pragas hematófagas de seres humanos e animais domésticos, afetando enormes parcelas da população (ARAÚJO-COUTINHO et al., 1999).

Desde a década de 1980, o Programa Africano de Controle da Oncocercose utiliza produtos à base de Bacillus thuringiensis israelensis (Bti) para controle de dípteros Simuliidae (HOUGARD et al., 1997). Esse programa conta com a capacitação das comunidades locais para atuar no controle do inseto vetor da chamada cegueira dos rios, que é um grande problema na saúde local (HOUGARD et al., 1997).

No Brasil, três programas de controle de simulídeos foram implantados. No território brasileiro, os simulídeos são encontrados nos estados de Mato Grosso, Minas Gerais, Bahia, Espírito Santo, Rio de Janeiro, São Paulo, Paraná, Santa Catarina, Rio Grande do Sul (NEVES, 1991). Um programa pioneiro no controle de simulídeos foi instalado no Estado do Rio Grande do Sul (RUAS NETO et al., 1984; RUAS NETO et al., 1985; SOUZA et al., 1994). 0 segundo programa no litoral norte do Estado de São Paulo (ARAUJO-COUTINHO \& LACEY, 1990; ANDRADE \& CASTELLO-BRANCO JR., 1991; RABINOVITCH et al., 2008) e o terceiro no Paraná (LOZOVEl et al., 1992; CUNHA \& BASSI, 1997).

O Programa de Controle de Simuliidae no Rio Grande do Sul se iniciou com a intenção de reduzir a incidência do inseto no local, reduzindo sua população (MARDINI \& SOUZA, 1998). Para atingir esse objetivo, foram utilizados manejo ambiental e ações de proteção e remediação ambiental, de maneira a melhorar a qualidade de vida das comunidades atingidas pelos simulídeos (MARDINI \& SOUZA, 1998). 0 programa passou a usar biolarvicidas à base de Bti ao invés de inseticidas químicos, pois as populações de S. pertinax apresentaram resistência aos pesticidas químicos (RUAS NETO, 1984a,b).

Em São Paulo, a Superintendência de Controle de Endemias (SUCEN), tem como alvo principal o S. pertinax que, segundo Araujo-Coutinho et al. (1988), é a espécie-alvo, uma vez que tem ampla densidade, distribuição e acentuada atividade antropofílica. O programa implantado para controle de simulídeos, assim como o no Rio Grande do Sul, substituiu inseticidas químicos por Bti, fazendo uso exclusivo dele desde 1990 (ARAÚJO-COUTINHO et al., 1999).

\section{PANORAMA E PERSPECTIVAS}

Simulídeos são insetos de interesse médico e veterinário por serem apontados como vetores de doenças causadas em decorrência do hábito hematófago das fêmeas e que atinge, também, o desenvolvimento econômico de algumas regiões turísticas. Considerados insetos-praga, necessitam da aplicação de formas de controle, a fim de diminuir sua densidade e os impactos causados. 
O controle químico é realizado através do uso de substâncias químicas, os inseticidas e larvicidas, para eliminar a espécie alvo. Apesar de eficaz inicialmente, a aplicação dos produtos pode afetar negativamente o ambiente, principalmente por sua alta toxicidade e acúmulo residual. 0 controle biológico é uma alternativa à utilização desses produtos químicos, sendo um importante componente no manejo ecológico de pragas e podendo ser realizado por meio da reprodução de predadores em laboratório e inserção dos mesmos no ambiente, onde as espécies alvo se encontram, com aplicação de inseticidas biológicos seletivos, preservação de áreas naturais propícias para desenvolvimento e alimentação dos agentes de controle biológico. Essa forma de controle apresenta grandes vantagens quando comparada ao controle com produtos químicos, como a especificidade contra organismos alvo e o baixo custo na aplicação. No entanto, apresenta algumas desvantagens, pois têm ação mais lenta, requer maior tecnologia para pesquisa de potenciais impactos ambientais e econômicos do organismo e produção de predadores em laboratório e são suscetíveis as condições climáticas.

O controle biológico de simulídeos é, hoje, uma alternativa ainda pouco utilizada em território nacional; entretanto, outros estudos sobre agentes entomopatogênicos de simulídeos se fazem necessários e, à medida que o lastro de conhecimento acerca dos padrões de ação, epizootia e enzootia desses entomopatógenos crescer, haverá um aumento da viabilidade de programas de controle biológico que possam substituir os programas baseados em agentes químicos, se apresentando como uma alternativa menos impactante ao meio ambiente.

\section{AGRADECIMENTOS}

Agradecemos o apoio da FAPERJ (Fundação Carlos Chagas Filho de Amparo à Pesquisa do Estado do Rio de Janeiro). 


\section{REFERÊNCIAS BIBLIOGRÁFICAS}

ADLER, P. H.; CROSSKEY, R. W. World Black Flies (Diptera: Simuliidae): a comprehensive revision of the taxonomic and geographical inventory. 2012. Disponível em: <http://www.clemson.edu/cafls/ departments/esps/biomia/pdfs/> Acesso em: 29 jun. 2013.

ADLER, P. H.; MCCREADIE, J. W. The hidden ecology of black flies: sibling species and ecological scale. American Entomologist, v. 43, p. 153-161, 1997.

AMARAL-CALVÃO, A. M. R.; MAIA-HERZOG, M. Coleção de simulídeos (Díptera:Simuliidae) de Adolpho Lutz, sua história e importância. História, Saúde e Ciências, v. 10, p. 259-271, 2003.

ANDERSON, G.R. Isolation virus from Diptera in Wisconsin. Mosquito News, v. 21, p. 224-228, 1961.

ANDRADE, C. F. S. Resistência de populações de simulídeos à inseticidas. In: Anais do Seminário Nacional de Vetores Urbanos e Animais Sinantrópicos, Porto Alegre, 1988. p. 59-60.

ANDRADE, C. F. S.; CASTELLO-BRANCO JR., A. Susceptibilidade de populações de Simulium (Chirostilbia) pertinax Kollar, 1832 (Culicomorpha, Simuliidae) ao temephos e a um formulado à base de Bacillus thuringiensisvar. israelensis. Revista de Saúde Pública, v. 25, p. 367-370, 1991.

ANDRADE, C. F. S. Controle Biológico de Borrachudos - Dosagens de produtos à base de Bacillus thuringiensis var. israelensis. Artigos Técnicos - Unicamp, Instituto de Biologia, Dep. de Zoologia, Campinas, 2008. Site Ecologia Aplicada, 2008. Disponível em: < http://www.ib.unicamp.br/profs/ eco_aplicada/> Acesso em: 11 ago. 2013.

ANDREWS, R. E., FAUST JR., R. M.; WABIKO, H.; RAYMOND, K. C.; BULLA, L. B. The biotechnology of Bacillus thuringiensis. CRC Critical Reviews of Biotechnology, v. 6, p. 163-232, 1987.

ARAÚJO-COUTINHO, C. J. P. C.; MAIA-HERZOG, M.; SOUZA, B. C. Levantamento das espécies do gênero Simulium latreille (Diptera: Simuliidae) no litoral norte do Estado de São Paulo. Revista Brasileira de Entomologia, v. 32, 1988.

ARAÚJO-COUTINHO, C. J. P. C.; LACEY, L. Controle de Simulídeos com concentrado emulsionável de Bacillus thuringiensis. Boletin de la Ofificna Sanitaria Panamericana, v. 108, p. 213-219, 1990.

ARAÚJO-COUTINHO, C. J. P. C.; MELLO, R. P.; FREIRE, N. M. S. The seasonal abundance of Simulim (Chirostilbia) pertinax, Kollar 1832, (Diptera, Simuliidae) and reated entomological fauna in the municipality of Paraty, RJ, Brasil. Revista Universidade Rural - Série Ciências da Vida, v. 21, p. 107-116, 1999.

ARAÚJO-COUTINHO, C. J. P. C.; NASCIMENTO, E. S.; FIGUEIRÓ, R.; BECNEL, J. J. Seasonality and prevalence rates of microsporidia in Simulium pertinax (Diptera: Simuliidae) larvae in the region of Serra dos Orgãos, Rio de Janeiro, Brasil. Journal of Invertebrate Pathology, v. 85, p. 188-191, 2004.

ARAUJO-COUTINHO, C. J. P. C.; FIGUEIRÓ, R.; VIVIANI, A. P.; NASCIMENTO, E. S.; CAVADOS, C. F. G. A bioassay method for blackflies (Diptera: Simuliidae) using larvicides. Neotropical Entomology, v. 34, p. $511-513,2005$.

BABA, M.; TAKAOKA, H. Oviposition habitats of a univoltine blackfly, Prosimulium kiotoense (Diptera: Simuliidae), in Kyushu, Japan. Medical and Vetenary Entomology, v. 5, p. 351-357, 1991. 
BARJAC, $\mathrm{H}$. Une nouvelle variete de Bacillus thuringiensis tre toxique pour les moustiques: B. thuringiensis var. Israelensis serotype H14. Comptes Rendues de la Académie de Sciences, v. 286, p. $797-800,1978$.

BECKER, N.; ZGOMBA, M.; LUDWIG, M.; PETRIC, D.; RETTICH, F. Factors influencing the activity of Bacillus thuringiensis sorovar israelensis treatments. Journal of the American Mosquito Control Association, v. 8, p. 285-289, 1992.

BERTAZO, K.; FIGUEIRÓ, R. Spatial distribution of black fly (Diptera: Simuliidae) immatures in a water current velocity gradient in Aracruz/ES, Brazil. Revista Universidade Rural, v. 32, p. 91-101, 2012.

BRAVO, A.; GILL, S.; SOBERÓN, M. Mode of action of Bacillus thuringiensis Cry and Cyt toxins and their potential for insect control. Toxicon, v. 49, p. 423-435, 2007.

BROWN, M. D.; DARRAN, T. K. W.; BRIAN, H. K. Laboratory and field evaluation of efficacy of Vectobac ${ }^{\circledR}$ 12 AS against Culex sitiens (Diptera: Culicidae) larvae. Journal of the American Mosquito Control Association, v. 14, p. 183-185, 1998a.

BROWN, M. D.; DARRAN, T.; BRIAN, H.K. Acute Toxicity Of Selected pesticides to the pacific blueeye,Pseudomugil signifer (Pisces). Journal of the American Mosquito Control Association, v. 14, p. 463-466, 1998b.

Brown, M. D.; Darran, T.; Paul, M.; Jack, G. G.; Brian, H. K. Laboratory and field evaluation of the efficacy of four insecticides for Aedes vigilax (Diptera: Culicidae) and toxicity to the nontarget shrimp Leander tenuicornis (Decapoda: Palaemonidae). Journal of Economic Entomology, v. 92, p. 1045-1051, 1999.

Brown, M. D.; Tonya, M. W.; Susannah, G.; Jack, G. G.; David, P.; Brian, H. K. Toxicity of insecticides for control of freshwater Culex annulirostris (Diptera: Culicidae) to the nontarget shrimp, Caradina indistincta(Decapoda: Atyidae). Journal of Economic Entomology, v. 93, p. 667-672, 2000.

CAMPOS, J. G.; ANDRADE, C. F. S. Considerações sobre os Simulídeos (Diptera, Nematocera) e o seu controle. Entomologia y Vectores, v. 8, p. 27-50, 2001.

CAVADOS, C. F. G.; FONSCECA, R. N.; CHAVES, J. Q.; ARAÚJO-COUTINHO, C. J. P. C.; RABINOVITCH, L. A new black fly isolate of Bacillus thuringiensis autoagglutinating strain highly toxic to Simuliium pertinax (kollar) (Diptera, Simuliidae) larvae. Memórias Instituto Oswaldo Cruz, v. 100, p. 795-797, 2005.

CERQUEIRA, N. L. Simuliidae da Amazônia III: Sobre o Gênero "Simulium" Latreille, 1802 (Diptera, Nematocera). Atas do Simpósio sôbre a Biota Amazônica (Zoologia) v. 5, p. 127-139, 1967.

CHANCE, M. M. The functional morphology of the mouthparts of blackfly larvae (Diptera: Simuliidae). Quaestiones Entomologicae, v. 6, p. 245-84, 1970.

CHILCOTT, C. N.; KNOWLES, B. H.; ELLAR, D. J.; DROBNIEWSKI, F. A. Mechanism of action of Bacillus thuringiensis israelensis parasporal body. In: Barjac, H.; Sutherland, D. J. (eds.) Bacterial Control of Mosquitoes and Black Flies. New Jersey: Rutgers University Press, 1990, p. 45-65.

CHUNG, Y. K.; PHUA-LAM, S. G.; CHUA, Y. T.; YATIMAN, R. Evaluation of biological and chemical inseticide mixture against Aedes aegypti larvae and adults by thermal fogging in Singapore. Medical and Veterinary Entomology, v. 15, p. 321-327, 2001. 
COLBO, M. H.; THOMPSON, B. H. An efficient technique for laboratory rearing of Simulium verecundum S. \& J. (Diptera: Simuliidae). Canadian Journal of Zoology, v. 56, p. 507-510, 1978.

COSCARÓN, S. Notas sobre simúlidos Neotropicais. XI. Sobre el subgênero Simulium (Chirostilbia) Enderlein, con la descripcíon de dos especies nuevas del S.E. del Brasil (Diptera, Insecta). Revista de la Sociedad Entomologica Argentina, v. 40, p. 157-164, 1981.

COSCARÓN, S. Fauna de água dulce de la República Argentina. Insecta, Diptera, Simuliidae. Buenos Aires: FECIC, 1991.

COUCH, T. L. Industrial fermentation and formulation of entomopathogenic bacteria. In: CHARLES, J. F.; DELÉCLUSE, A.; NIELSEN-LEROUX, C. (eds.) Entomopathogenic bacteria: From laboratory to field application. XX ed. Dordrecht: Kluwer Academic Publishers, 2000. p. 297-314.

CROSSKEY, E. W. Observations on the bionomics of adult Simulium damnosum Theobald (Diptera: Simuliidae) in northern Nigeria. Annals of Tropical Medicine and Parasitology, v. 49, p. 142-153, 1955.

CROSSKEY, R. W. The natural history of blackflies. London: Jon Wiley \& Sons Editora, 1990.

CROSSKEY, R. W.; HOWARD, T. M. A revised taxonomic and geographical inventory of world blackflies (Diptera: Simuliidae). London: The Natural History Museum, 2004.

CUMMINS, W. Trophic relations of Aquatic insects. Annual Review of Entomology, v. 18, p.183-206, 1973.

Cunha, M. C. I.; Bassi, R. M. A. Ensayo con Bacillus thuringiensis var. israelensis sobre simúlidos (Diptera, Simuliidae) en el río São João, Paraná, Brasil. Acta Biológica Paranaense, v. 26, p. 9-21, 1997.

DALMAT, H. T. Black flies (Diptera, Simuliidae) of Guatemala of Onchocerciasis and their role as vectors of onchocerciasis. Washington: Smithsonian Institute, Smith. Misc. Col., 1955.

DELMONTES, S.; KANITAKIS, J.; COZZANI, E.; PARODI, A.; REBORA, A. Diagnosing pemphigus foliaceus: a retrospective analysis of clinical, histological and immunological criteria. Dermatology, v. 203, p. 289-293, 2001.

EATON, D. P.; DIAZ, L. A.; HANS-FILHO, G.; SANTOS, V.; AOKI, V.; FRIEDMAN, H.; RIVITTI, E. A.; SAMPAIO, S. A. P.; GOTTLIEB, M. S.; GIUDICE, G. J.; LOPEZ, A.; CUPP, E. W. Comparison of Black Fly Species (Diptera: Simuliidae) on na Amerindian Reservation with a High Prevalence of Fogo Selvagem to Neighboring Disease-Free Sites in the State of Mato Grosso do Sul, Brazil. Journal of Medical Entomology, v. 35, p. 120-131, 1998.

FIGUEIRÓ, R.; ARAUJO-COUTINHO, C. J.; AZEVEDO, L. H.; NASCIMENTO, E. S.; MONTEIRO, R. F. Spatial and temporal distribution of blackflies (Diptera: Simuliidae) in the Itatiaia National Park, Brazil. Neotropical Entomology, v. 35, p. 542-550, 2006 .

FIGUEIRÓ, R.; NASCIMENTO, E. S.; GIL - AZEVEDO, L. H.; MAIA- HERZOG, M.; MONTEIRO, R. F. Local distribution of blackfly (Diptera, Simuliidae) larvae in two adjacent streams: the role of water current velocity in the diversity of blackfly larvae. Revista Brasileira de Entomologia, v. 52, p. $452-454,2008$.

FIGUEIRÓ, R.;FIGUEIRÓ, RONALDO2006FIGUEIRÓ, R.; DOCILE, T. N.; ARANDA, A. T. An Artificial Breeding Site for Larvicide Bioassays with Blackfly (Diptera:Simuliidae) Larvae and other Macroinvertebrates from lotic systems. BioAssay, v. 1, p. 1-11, 2006b. 
FIGUEIRÓ, R.; MAIA-HERZOG, M.; GIL-AZEVEDO, L. H.; MONTEIRO, R. F. Diversity and microdistribution of black fly (Diptera: Simuliidae) assemblages in the tropical savanna streams of the Brazilian cerrado. Memórias do Instituto Oswaldo Cruz (Impresso), v. 107, p. 362-369, 2012.

FILINGER, U.; KNOLS, B. G. J.; BECKER, N. Efficacy and efficiency of new Bacillus thuringiensis var. israelensis and Bacillus sphaericus formulations against Afrotropical anophelines in Western Kenya. Tropical Medicine and International Health, v. 8, p. 37-47, 2003.

FIUZA, L. M.; NIELSEN-LEROUX, C.; GOZE, E.; FRUTOS, R.; CHARLES, J. F. Binding of Bacillus thuringiensis Cry1 toxins to the midgut brush border membrane vesicles of Chilo suppressalis (Lepidoptera, Pyralidae): evidence of shared binding sites. Applied Environmental Microbiology, v. 62, p.1544-1549, 1996.

FORATTINI, O. P. Culicidologia Médica. São Paulo: EDUSP, 2002.

FREDEEN, F. J. H. Rearing Black Flies in the Laboratory (Diptera: Simuliidae). Canadian Entomologist, v. 91, p. $73-83,1959$.

GAUGLER, R.; MOLLOY, D.; HASKINS, T.; RIDER, G. A bioassay system for the evaluation of black fly (Diptera: Simuliidae) control agents under simulated stream conditions. Canadian Entomologist, v. 112, p. 1271-1276, 1980.

GIL-AZEVEDO, L. H.; SANTOS-MALLET, J. R.; MAIA-HERZOG, M. Caracteres diagnósticos de Simulium (Chirostilbia) pertinax Kollar (Diptera: Simuliidae). Neotropical Entomology, v. 33, p. 433-437, 2004.

GLARE, T. R.; O' CALLAGHAN, N. M. Environmental and Health Impacts of Bacillus thuringiensis israelensis. Report for the Ministry of Health, Grasslands, New Zealand. Lincoln: Division AgResearch, 1998.

GINARTE, C. A.; ANDRADE, C. F. S.; GAONA, J. C. Larvas de simulídeos (Diptera, Simuliidae) do centro oeste, sudeste e sul do Brasil, parasitadas por microsporídeos (Protozoa) e mermitídeos (Nematoda). Iheringia - Sér. Zool., v. 93, p. 325-334, 2003.

HAMADA, N. Association between Hemerodromia sp. (Diptera, Empididae) and Simulium perflavum (Diptera, Simuliidae) in Central Amazonia, Brazil. Memórias do Instituto Oswaldo Cruz, v. 88, p. 169170, 1993.

HART, D. D.; MERZ, R. A.; GENOVESE, S. J.; CLARK, B. D. Feeding postures of suspension-feeding larval black flies: the conflicting demands of drag and food acquisition. Oecologia, v. 85, p. 457-463, 1991.

HARTLEY, C. F. Rearing simuliids in the laboratory from eggs to adults. Proceedings of the Helminthological Society of Washington, v. 22, p. 93-95, 1955.

HEMBREE, S. C.; FROMMER, R. L.; REMINGTON, M. P. A bioassay apparatus for evaluating larvicides against black flies. Mosquito News, v. 40, p. 647-650, 1980.

HERRERO, S.; OPPERT, B.; FERRÉ, J. Different mechanisms of resistance to Bacillus thuringiensis toxins in the indianmeal moth. Applied and Environmental Microbiology, Washington, v. 67, p.1085-1089, 2001.

HÖFTE, H.; WHITELEY, H. R. Insecticidal crystal proteins of Bacillus thuringiensis. Microbiological Reviews, v.53, p.242-255, 1989. 
HOUGARD, J-M.; YAMÉOGO, L.; SÉKÉTÉLI, A.; BOATIN, B.; DADZIE, K. Y. Twenty-two years of blackfly control in the Onchocerciasis control programme in West Africa. Parasitology Today, v. 13, p. 425-431, 1997.

HYNES, H. B. N. The biology of polluted waters. Toronto: University of Toronto Press, 1974.

JAMNBACK, H. The origins of blackfly control programmes. In: LAIRD, M. (ed.) Blackflies - The Future for Biological Methods in Integrated Control. New York and Londres: Academic Press, 1981.

JAMNBACK, H.; FREMPONG-BOADU, J. Testing black fly larvicides in the laboratory and in streams. Bulletin of World Health Organization, v. 34, p. 405-421, 1966.

JEAN-FRANÇOIS, C.; NIELSEN-LEROUX, C. Mosquitocidal Bacterial Toxins: Diversity Mode of Action and Resistance Phenomena. Memórias do Instituto Oswaldo Cruz, v. 95, p. 202-206, 2000.

JOUNG, K. B.; COTÉ, J. C. A Review of the Environmental Impacts of the Microbial Insecticide Bacillus thuringiensis. Tecnical Bulletin, $n^{\circ}$ 29, Québec, 16 p. 2000.

KIEL, E.; BOGE, F.; RUHM, W. Sustained effects of larval blackfly settlement on further substrate colonisers. Archiv fur Hydrobiologie, v. 141, p. 153-166, 1998.

KIKUCHI, R. M.; UIEDA, V. S. Composição da comunidade de invertebrados de um ambiente lótico tropical e sua variação espacial e temporal. In: Nessimian, J. L.; Carvalho, E. (eds.) Ecologia de insetos aquáticos. Rio de Janeiro: PPGE-UFRJ, Série Oecologia Brasiliensis, vol. 5, 1998. p. 157-173.

LACEY, L. A.; MULLA, M. S. A new bioassay unit for evaluating larvicides against black flies. Journal of Economical Entomology, v. 70, p. 453-456, 1977.

LACEY, L. A.; LACEY, J. M. The larvicidal activity of Bacillus thuringiensis var. israelensis (H-14) against mosquitoes of the central Amazon basin. Mosquito News, v. 41, p. 266-270, 1981.

LACEY, L. A.; UNDEEN, A. H. The effect of formulation, concentration, and application time on the efficacy of Bacillus thuringiensis ( $\mathrm{H} 14)$ against black fly larvae under natural conditions. Journal of Economical Entomology, v. 77, p. 412-418, 1984.

LACEY, L. A.; FRUTOS, F.; KAYA, H. K.; VAIL, V. Insect Pathogens as Biological Control Agents: Do They Have a Future?. Biological Control, v. 21, p. 230-248, 2001.

LANE, J. Dados sobre os simulídeos de localidades onde ocorreram casos de Penfigo Foliáceo. Arquivos de Higiene e Saúde Publica, v. 3, p. 53-54, 1949.

LERECLUS, D. Génétique et biologie moléculaire de Bacillus thuringiensis. Bulletin de I'Institut Pasteur, v.86, p. 337-371, 1988.

LOZOVEI, A. N.; CUNHA, M. C. I.; OLIVEIRA, V. L. R. Controle físico de Simulídeos (Diptera: Simuliidae) em vertedouros de açudes de piscicultura e no leito do Rio Don Rodrigo, Campo Largo, Paraná, Brasil. Arquivos de Biologia e Tecnologia, v. 35, p. 679-684, 1992.

MARDINI, L. B. L. F.; SOUZA, M. A. T. Programa Estadual de Controle do Simulium spp. no Rio Grande do Sul - A importância do método de vazão. Anais do III Seminário Nacional de Zoonoses e Animais Peçonhentos, p. 112, 1998. 
MEDEIROS, J. F.; PY-DANIEL, V.; BARBOSA, U. C.; Ogawa, G. M. Ocorrência da Mansonella ozzardi (Nematoda, Onchocercidae) em comunidades ribeirinhas do rio Purus, Município de Boca do Acre, Amazonas, Brasil. Cadernos de Saúde Pública (ENSP. Impresso), v. 25, p. 1421-1426, 2009.

MUIRHEAD-THOMSON, R. C. Laboratory studies on the reactions of Simulium larvae to insecticides. American Journal of Tropical Medicine and Hygiene, v. 6, p. 920-925, 1957.

NASCIMENTO, E. S.; FIGUEIRÓ, R.; BECNEL, J. J.; ARAÚJO-COUTINHO, C. J. P. C. Influence of temperature on microsporidia infections in a natural population of Simulium pertinax Kollar, 1832 (Diptera; Simuliidae). Brazilian Journal of Biology, v. 67, p. 519-526. 2007.

NAYAR, J. R.; KNIGHT, J. W.; CARLSON, D. B.; O'BRYAN, P. D. Laboratory evaluation of biotic and abiotic factors that may influence larvicidal activity of Bacillus thuringiensis serovar israelensis against two Florida mosquitoes species. Journal of the American Mosquito Control Association., v. 15, p. 32-42, 1999.

NEVES, D. P. Parasitologia Humana. 8 ed. São Paulo: Livraria Atheneu Editora, 1991.

PEFERÖEN, M. Progress and prospects for field use of Bt genes in crops. Trends in Biotechnology, v. 15, p. 173-177, 1997.

PEGORARO, R. A. Dispositivo para cri- ação de larvas e pupas de Simuliidae (Diptera) em condições semi-naturais. Anais da Sociedade Entomológica do Brasil, v. 18, p. 179-183, 1989.

PEPINELLI, M.; TRIVINHO-STRIXINO, S.; HAMADA, N. Description of Simulium (Chirostilbia) friedlanderi Py-Daniel, 1987 (Insecta: Diptera: Simuliidae) female. Biota Neotropica, v. 3, p. 1-7, 2003.

PINTO, C. Simuliidae da América Central e do Sul (Diptera). Reunião da Sociedade Argentina de Patologia Regional do Norte, p. 661-763, 1931.

RABINOVITCH, L.; ARAUJO-COUTINHO, C. J.; SILVA, C. M. B.; ALVES, R. S. A.; ALVES, L. F. A.; CAVADOS, C. F. G. Bioprodutos à base de Bacillus entomopatogenicos em programas de controle de vetores na America Latina. In: ALVES, S. B. (ed.) Controle microbiano Pragas na América Latina - Avanços e Desafios. Piracicaba: Fundação de Estudos Agrários Luiz de Queiroz, 2008. p. 137-170.

REY, L. Parasitologia - Parasitos e Doenças Parasitarias do Homem nos Trópicos Ocidentais. $4^{\mathrm{a}}$ ed. Rio de Janeiro: Guanabara Koogan, 2008.

RODRIGUES, I. B.; WANDERLI, P.T.; JOSÉ, M. C. S. D. Studies on the Bacillus sphaericus larvicidal activity against Malarial Vector Species in Amazonia. Memórias do Instituto Oswaldo Cruz, v. 93, p. 441- 444, 1998.

RUAS NETO, A. L. Avaliação do uso de temephos para o controle de culicídeos e simulídeos no Rio Grande do Sul. Boletim de Saúde, v. 11, p. 27-31, 1984a.

RUAS NETO, A. L. Bacillus thuringiensis var. israelensis, como alternativa no controle de simulídeos no Rio Grande do Sul.1. Susceptibilidade a campo. Boletim de Saúde, v. 11, p. 21-26, 1984b.

RUAS NETO, A. L.; PACHECO, E.; TORRES, M. A. Projeto de controle de simulídeos, plano de pesquisa e dados coligidos. Boletim de Saúde, v. 11, p. 17-20, 1984. 
RUAS NETO, A. L.; SOUZA, M. A. T.; SEVERINO, S.; MELO, J. L. B.; SILVEIRA, S. M.; FONTES, N. D. F. Controle integrado do Simulium (Chirostilbia) pertinax Kollar, 1822 - Utilização de Bacillus thuringiensis var. israelensis no Rio Grande do Sul. Boletim de Saúde, v. 12, p. 17-20, 1985.

SAMPAIO, S. A.; RIVITTI, E. A.; AOKI, V.; DIAZ, L. A. Brazilian pemphigus foliaceus, endemic pemphigus foliaceus, or fogo selvagem (wild fire). Dermatologic Clinics, v. 12, p. 765-776, 1994.

SANTOS-JR, J. E.; STRIEDER, M. N.; FIORENTIN, G. L.; NEISS, U. G. Velocidade da água e a distribuição de larvas e pupas de Chirostilbia pertinax (Kollar, 1832) (Diptera: Simuliidae) e macroinvertebrados associados. Revista Brasileira de Entomologia, v. 51, p. 62-66, 2007.

SCHNEPF, E.; CRICKMORE, N.; VANRIE, J.; BAUM, J.; FEITELSON, J.; ZEIGLER, D. R.; DEAN, D. H. Bacillus thuringiensis and its pesticidal crystal proteins. Microbiology Molecular Biology Review, v. 62, p. 775-806, 1998.

SILVEIRA, G. L.; TUCCI, C. E. M.; SILVEIRA, A. L. L. Quantificação de vazão em pequenas bacias sem dados. Revista Brasileira de Recursos Hídricos, v. 3, p. 111-113, 1998.

SOUZA, M. A. T.; MARDINI, L. L. F.; GOMES, E. C.; SILVEIRA, G. L. Evolução do Controle Biológico de Simulídeos através do Bacillus thuringiensis var. israelensis no Rio Grande do Sul, Brasil. Informe do Programa Estadual de Controle dos Simulídeos da Divisão de Zoonoses e Vetores da Secretaria de Saúde e Meio Ambiente, v. 15, p. 261-278, 1994.

STAHLY, D. P.; ANDREWS, R. E.; YOUSTEN, A. A. The genus Bacillus - insect pathogens. In: The Prokaryotes. 2 ed. New York: Springer, 1991.

SIEGEL, J. P. The mammalian safety of Bacillus thuringiensis-based insecticides. Journal of Invertebrate Pathology, v. 77, p. 13-21, 2001.

STRIEDER, M. N.; CORSEUIL, E. Atividades de hematofagia em Simuliidae (Diptera, Nematocera) na Picada Verão, Sapiranga, RS, Brasil. Acta Biologica Leopoldensia, v. 14, p. 75-97, 1992.

VIVIANI, A. B. P.; ARAÚJO-COUTINHO, C. J. P. C. Influência da Temperatura no desenvolvimento embrionário de Simulium pertinax Kollar, 1832 (Diptera: Simuliidae). Entomología y Vectores, v. 6, p. 591-600, 1999.

VILARINHOS, P. T. R.; DIAS, D. G. S.; MONNERAT, R. G. Persistência larvicida de formulações de Bacillus thuringiensis subsp. israelensis para o controle de larvas de

AEDES AEGYPTI. Brasília: Embrapa Recursos Genéticos e Biotecnologia, Boletim de Pesquisa e Desenvolvimento, n. 39, 2003.

VILAS-BOAS, G. F. L. T.; PERUCA, A. P. S.; ARANTES, O. M. N. Biology and taxonomy of Bacillus cereus, Bacillus anthracis and Bacillus thuringiensis. Canadian Journal of Microbiology, v. 53, p. 673-687, 2007.

VOJVODIC, S.; NELDER, M. D.; McCREADIE, J. W. Influence of fixation of the blackfly Simulium vittatum on morphological characters of the trichomycete Smittium culisetae. Acta Entomologica Serbica, Suplemento, p. 125-130, 2006.

WALLACE, J. B.; MERRIT, R. W. Filter-feeding ecology of aquatic insects. Annual Review of Entomology, v. 25, p. 103-132, 1980.

ZHANG, Y. Balancing food availability and hydrodynamic constraint: phenotypic plasticity and growth in Simulium noelleri blackfly larvae. Oecologia, v. 147, p. 39-46, 2006. 